\section{Commentary: Hepatocellular carcinoma after the Fontan operation: Are we paying attention?}

\author{
Harold M. Burkhart, MD, ${ }^{a}$ and \\ Sabrina D. Phillips, $\mathrm{MD}^{\mathrm{b}}$
}

The surgical management of functional single-ventricle patients has progressed since the introduction of the Fontan operation, with modifications being focused on a more efficient, nonobstructed systemic venous circuit. While surgical adjustments, along with advances in medical management, have improved outcomes and lifespan for these complex patients, sequela related to chronic central venous hypertension and reduced cardiac output have become evident, affecting quality of life and long-term survival. The liver seems to be especially vulnerable to the effects of an elevated central venous pressure due to the lack of a pulmonary pump. In 2005 in The Journal of Thoracic and Cardiovascular Surgery, Ghaferi and Hutchins ${ }^{1}$ were the first to point out the progressive liver pathology in patients who underwent a Fontan procedure related to chronic increased hepatic venous pressure resulting in cirrhosis and even hepatocellular carcinoma. The high central venous pressure in the hepatic veins is transmitted to the hepatic sinusoids, likely reducing portal vein flow. The hepatic artery is unable to counteract the decrease in portal flow due to diminished cardiac output. These chronic

\footnotetext{
From the a Division of Cardiovascular and Thoracic Surgery, University of Oklahoma Health Sciences Center, Oklahoma City, Okla; and ${ }^{\mathrm{b}}$ Department of Cardiology, Mayo Clinic, Jacksonville, Fla.

Disclosures: The authors reported no conflicts of interest.

The Journal policy requires editors and reviewers to disclose conflicts of interest and to decline handling or reviewing manuscripts for which they may have a conflict of interest. The editors and reviewers of this article have no conflicts of interest.

Received for publication March 1, 2020; revisions received March 1, 2020; accepted for publication March 8, 2020; available ahead of print April 1, 2020.

Address for reprints: Harold M. Burkhart, MD, Division of Cardiovascular and Thoracic Surgery, University of Oklahoma Health Sciences Center, P.O. Box 26901, WP-2230, Oklahoma City, OK 73105 (E-mail: Harold-burkhart@ouhsc. edu).

JTCVS Techniques 2020;2:133-4

2666-2507

Copyright (C) 2020 The Authors. Published by Elsevier Inc. on behalf of The American Association for Thoracic Surgery. This is an open access article under the CC BY-NCND license (http://creativecommons.org/licenses/by-nc-nd/4.0/).

https://doi.org/10.1016/j.xjtc.2020.03.009
}

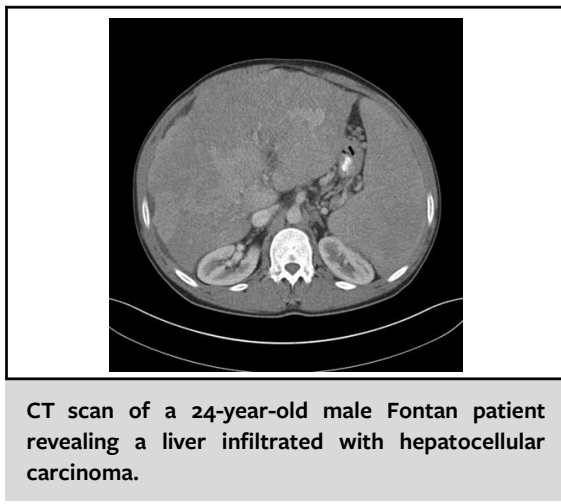

\begin{abstract}
CENTRAL MESSAGE
Knowing that hepatocellular carcinoma is part of the Fontanassociated liver disease spectrum should trigger us to understand the prevalence and prompt strict surveillance in hopes of having a favorable impact.
\end{abstract}

physiologic insults, magnified with increased demands on the heart, result in Fontan-associated liver disease. ${ }^{2}$

In this issue of JTCVS Techniques, Wilson and colleagues $^{3}$ present the first population-based report of hepatocellular carcinoma prevalence in patients undergoing a Fontan procedure. The data presented come from the unique Australian and New Zealand Fontan Registry, a database collecting follow-up data on all patients undergoing a Fontan procedure in their region. They report 1620 surviving patients who underwent a Fontan procedure over a 43-year period. With a mean follow-up time of 12.7 years in $96 \%$ of the patients who underwent a Fontan in the countries, only 5 patients $(0.3 \%)$ were diagnosed with hepatocellular carcinoma. The obvious strength of the manuscript is that, given the amount of attention Fontanassociated liver disease has received over the past decade, it is critical that steps be taken in the form of registries to define the prevalence of the disease. The authors have succeeded and given us perhaps encouraging news in reporting such a low prevalence of hepatocellular carcinoma. Furthermore, they point out that 4 of the 5 patients with hepatocellular carcinoma had reinterventions on their Fontan, theorizing that the failing Fontan procedures may be at most risk. Knowing the prevalence and standardizing follow-up, particularly for those at risk, may reduce the incidence. 
Although the report represents a solid step in the right direction in our search to understand the magnitude of the liver issue in patients undergoing a Fontan procedure, a few shortcomings should be discussed. While the rate of development of hepatocellular carcinoma reported in this cohort is small, the data reported here may not be so reassuring for this patient population, given the young age at diagnosis and the $100 \%$ mortality reported after diagnosis. Compared with populations with high rates of cirrhosis and hepatocellular carcinoma, such as the hepatitis $\mathrm{C}$-infected population, this patient population is significantly younger and appears to be developing hepatocellular carcinoma earlier in the context of their chronic liver disease. ${ }^{4}$ Also, it is unclear from this registry data how these patients were routinely followed. Each of the 5 patients described appear to be diagnosed in the context of imaging performed for symptoms or known cirrhosis. No patient appeared to have routine screening, so the incidence of hepatocellular carcinoma in the cohort could be greater but undiagnosed, as it is at an early stage. Data from other centers that demonstrate a greater rate of hepatocellular carcinoma do report routine surveillance strategies. ${ }^{5}$ Finally, it is unsupported by these data to state that patients who developed hepatocellular carcinoma after the Fontan procedure all have cirrhosis and portal hypertension. Again, there may be patients with early-stage disease who were not picked up and reported in this cohort. Previous data have been reported that demonstrate a significant population of patients who underwent a Fontan procedure without cirrhosis who developed hepatocellular carcinoma, which is distinct from other causes of hepatocellular carcinoma. ${ }^{6}$

In conclusion, the authors present the first populationbased prevalence of hepatocellular carcinoma in patients undergoing a Fontan procedure. It is clear that the congenital community needs to follow their lead in tracking patients undergoing a Fontan procedure and defining those at risk for Fontan-associated liver disease and hepatocellular carcinoma. Most adult patients will need at least annual surveillance imaging of the liver (Figure 1), with measurement of the tumor marker alpha fetoprotein to screen for hepatocellular carcinoma, and those with advanced liver disease should have this screening every 6 months. Patients with suspicious lesions on imaging require imaging-guided biopsy of the lesion, especially if alpha fetoprotein is elevated. Once Fontan-associated liver disease is identified, appropriate medical management includes an assessment of

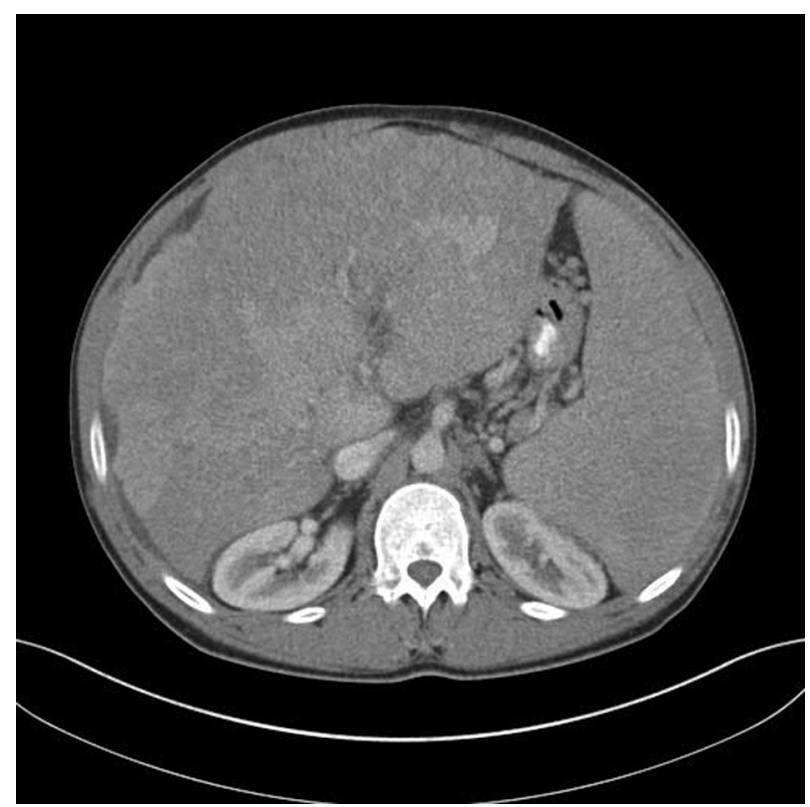

FIGURE 1. CT scan of a 24-year-old male Fontan patient revealing a liver infiltrated with hepatocellular carcinoma.

need for anticoagulation, as it may favorably impact the progression of chronic liver disease. ${ }^{7}$ Other drug therapies that should be considered include spironolactone, angiotensin-converting enzyme inhibition, and sildenafil, which may favorably improve hemodynamics and alter fibrosis in this population.

\section{References}

1. Ghaferi AA, Hutchins GM. Progression of liver pathology in patients undergoing the Fontan procedure: chronic passive congestion, cardiac cirrhosis, hepatic adenoma, and hepatocellular carcinoma. J Thorac Cardiovasc Surg. 2005;129: 1348-52.

2. Gordon-Walker TT, Bove K, Veldtman G. Fontan-associated liver disease: a review. J Cardiol. 2019;74:223-32.

3. Wilson TG, Iyengar AJ, Hardikar W, Sood S, d'Udekem Y. Prevalence of hepatocellular carcinoma in the entire Fontan population of Australia and New Zealand. J Thorac Cardiovasc Surg Tech. 2020;2:128-30.

4. Axley P, Ahmed Z, Ravi S, Singal A. Hepatitis C virus and hepatocellular carcinoma: a narrative review. J Clin Transl Hepatol. 2018;6:79-84.

5. Nandwana SB, Olaiya B, Cox K, Sahu A, Mittal P. Abdominal imaging surveillance in adult patients after Fontan procedure: risk of chronic liver disease and hepatocellular carcinoma. Curr Probl Diagn Radiol. 2018;47:19-22.

6. Egbe AC, Poterucha JT, Warnes CA, Connolly HM, Baskar S, Ginde S, et al. Hepatocellular carcinoma after Fontan operation. Circulation. 2018;138:746-8.

7. Villa E, Cammà C, Marietta M, Luongo M, Critelli R, Colopi S, et al. Enoxaparin prevents portal vein thrombosis and liver decompensation in patients with advanced cirrhosis. Gastroenterology. 2012;143:1253-60. 